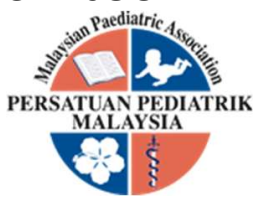

\title{
CONGENITAL BILATERAL DACRYOCYSTOCELE WITH NASAL PYRIFORM APERTURE STENOSIS
}

\author{
Muhammad Harith Mohamed Rouse ${ }^{1,2}$, Nor Shahida Abd Mutalib ${ }^{2}$, Nurliza Idris ${ }^{2}$, Azliana Aziz ${ }^{1}$
}

\begin{abstract}
Congenital bilateral dacryocystocele with concomitant congenital nasal pyriform aperture stenosis is a very rare case we seen in the paediatric age group. We report a case referred by the paediatric department to rule out choanal stenosis. The referring department had difficulty to insert a feeding tube to the patient. Nose and throat examination showed reduce misting on cold spatula test and unable to introduce nasoendoscope into both nostrils, which indicates obstruction. Radiological investigation revealed as congenital dacryocystocele with nasal pyriform aperture stenosis. The patient was managed surgically with good recovery.
\end{abstract}

Keywords: Congenital Dacryocystocele, Nasal Pyriform Aperture Stenosis, Congenital Anomalies, Choanal Stenosis

DOI: $10.51407 / \mathrm{mjpch} . v 27 i 1.133$

\section{Introduction}

Congenital dacryocystocele with congenital nasal pyriform aperture stenosis (CNPAS) is an uncommon congenital case. Usually, neither dacryocystocele nor nasal pyriform aperture stenosis will have both abnormalities at the same time. The congenital dacryocystocele is a rare pathology, with only $0.1 \%$ seen in infants with congenital nasolacrimal obstruction [1]. In congenital dacryocystocele, it usually occurs concomitant to obstruction of the upper and lower valve (Rossenmuller and Hasner valve). The sac filled with mucoid material with a grey-blue cystic swelling just below the medial canthus. However, in CNPAS, bony overgrowth of the maxillary processes is the causes. Its true incidence is still unknown. It is estimated that CNPAS has a reported incidence of 1 in 5,000 to 8,000 live birth $[2,3]$. It should be confirmed by computed tomography (CT) scan of the paranasal sinus. Both congenital, if bilaterally obstructed will cause of respiratory distress or feeding difficulties especially in newborn.
Received: 08 December 2020; Accepted revised

manuscript: 13 February 2021

Published online: 03 May 2021

\section{Case Report}

We report a case of a full-term infant of a mother with Gestational Diabetes Mellitus (GDM) who has been taking subcutaneous insulin during the pregnancy. At 40 hours of life, she was referred to Otorhinolaryngology team for stertor and suspected choanal stenosis as the paediatric team failed to insert suction tube size 5 over left nostril. On examination, the child has no dysmorphic features, mild tachypnoea with no stridor and the cold spatula test showed minimal fogging on the left side and good fogging on the right nostril. Flexible scope only able to visualize deviated bilateral nasal septum more on the left side and procedure was abandoned due to desaturation. Oxymetazoline nasal drop $0.01 \%$ was started and the patient was planned for $C T$ scan of the

\footnotetext{
'Department of Otorhinolaryngology- Head \& Neck Surgery, School of Medical Sciences, Universiti Sains Malaysia, 16150 Kota Bharu, Kelantan, Malaysia

${ }^{2}$ Department of Otorhinolaryngology, Hospital Sultan Abdul Halim, 08000 Sungai Petani, Kedah, Malaysia

Corresponding Author:

Dr Azliana Aziz, Department of OtorhinolaryngologyHead \& Neck Surgery, School of Medical Sciences, Universiti Sains Malaysia Health Campus, 16150 Kota Bharu, Kelantan, Malaysia

Tel: +609-7673000 ext: 6428 Email: az_aziz@usm.my
} 
paranasal sinus.

CT scan reported as bilateral soft tissue lesion medial to the globe likely lacrimal lesion, no fat content to suggest dermoid cyst (Figure 1), narrowing of bilateral nasal aperture suggestive of stenosis (Figure 2), and presence of solitary maxillary central mega incisor. Bilateral choana was normal. Thus proceed with magnetic resonance imaging (MRI) and reported as dilatation of the bilateral nasolacrimal ducts, and bilateral dacryocystocele measure $0.5 \mathrm{~cm} \times 0.6 \mathrm{~cm}$ on both sides (Figure 3). No brain tissue herniation was seen in this region.

The patient underwent marsupialization of dacryocystocele and drilling of the stenotic part. Operative findings showed narrowing of the bilateral nasal pyriform aperture with a deviated nasal septum to the left and bulging of the nasolacrimal duct (dacryocystocele), with normal choana opening bilaterally. The endotracheal tube size $3.5 \mathrm{~mm}$ was inserted as a stent into both nostrils.
After 3 days of post-operation, the patient was extubated well. Subsequently on day 7 postoperation, the stent was removed under general anaesthesia. After the operation, the cold spatula test was positive (fogged) bilaterally. The repeated flexible scope was done in the neonatal intensive care unit showed both nostril patents with minimal trauma at the right nostril. No adhesion or synechiae were seen.

The patient was then discharged home with nasal douching and reviewed after six weeks in the clinic. Clinically the baby was comfortable with no noisy breathing. Cold spatula test and flexible scope showed patent both nostrils.

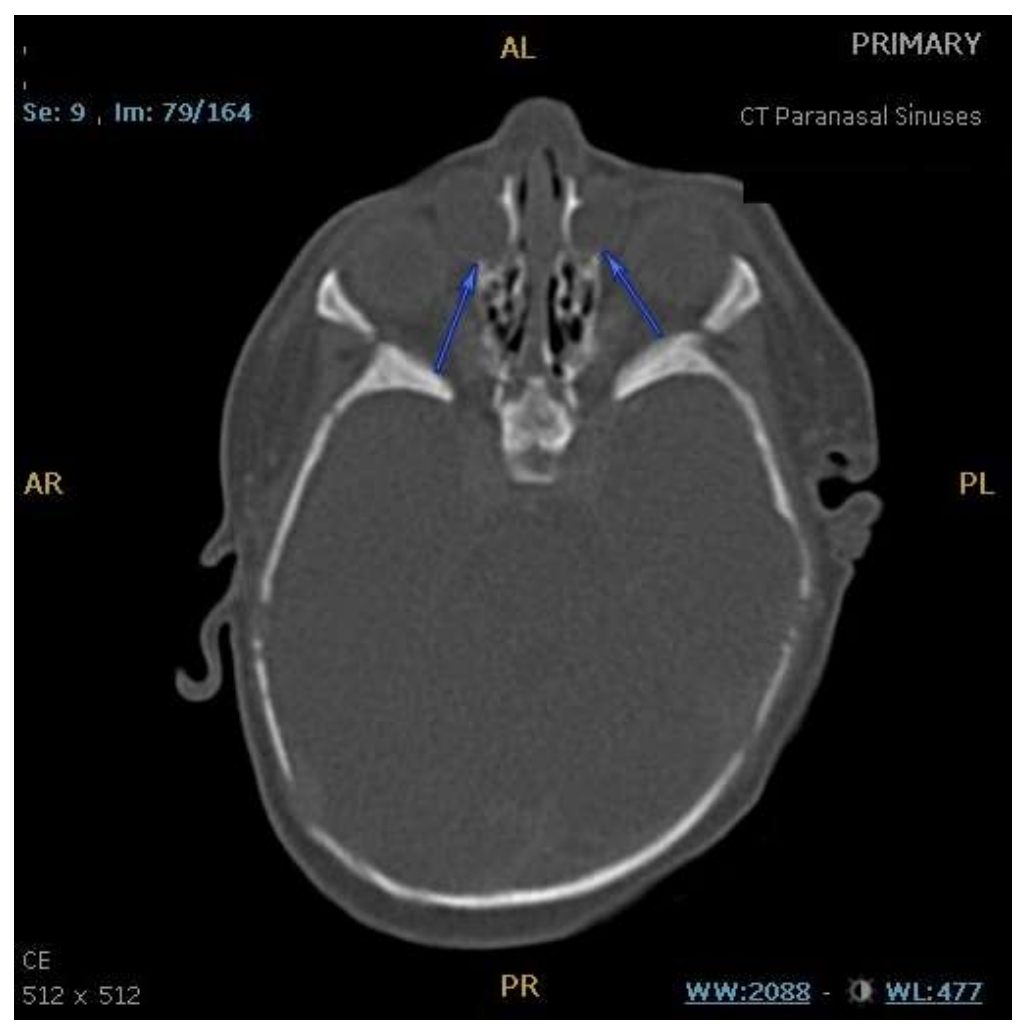

Figure 1. Axial view CT of paranasal sinus on the bone window. Blue arrow showed bilateral soft tissue lesion medial to the globe likely lacrimal lesion. 


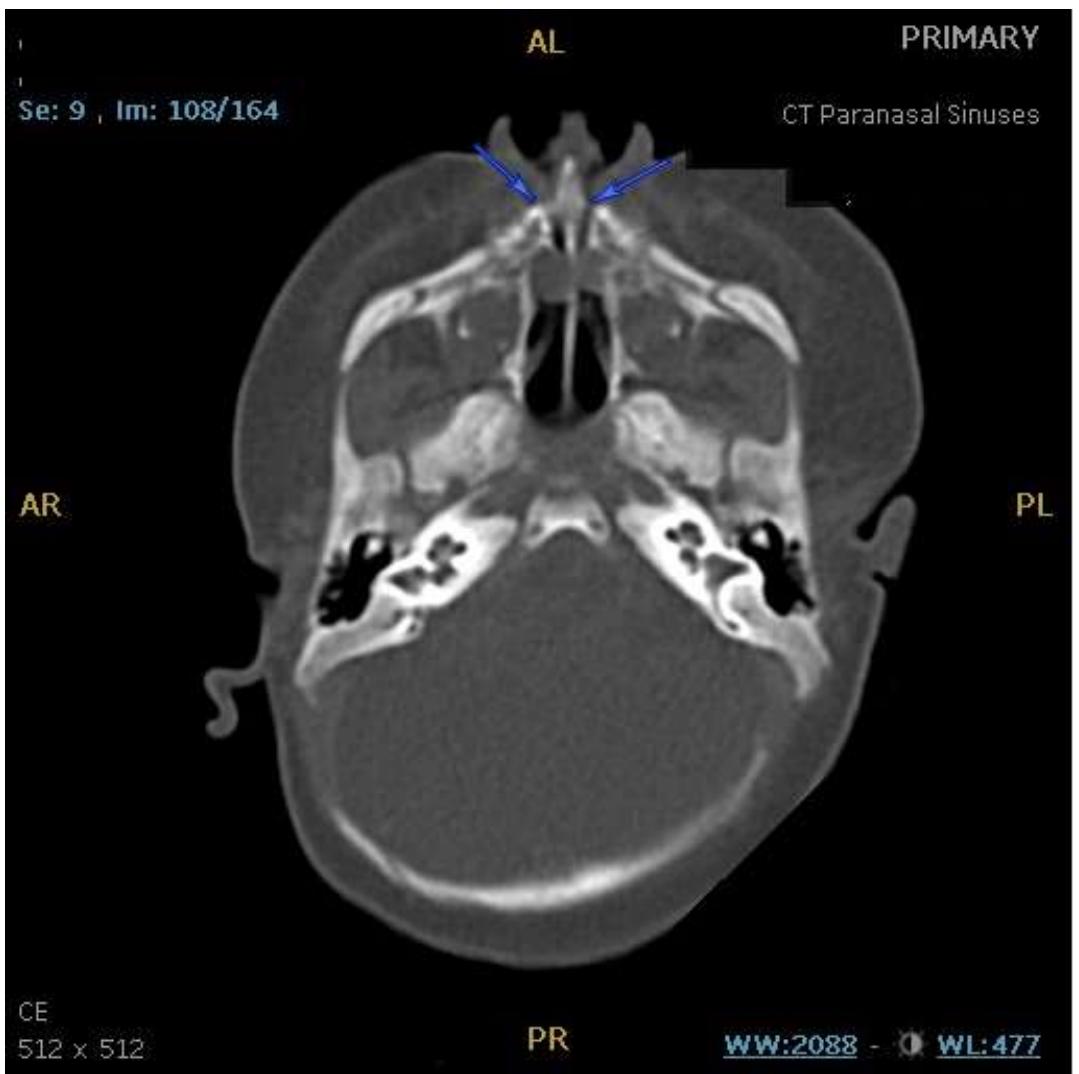

Figure 2. Axial view CT of paranasal sinus on the bone window. Blue arrow showed bilateral nasal pyriform aperture stenosis.

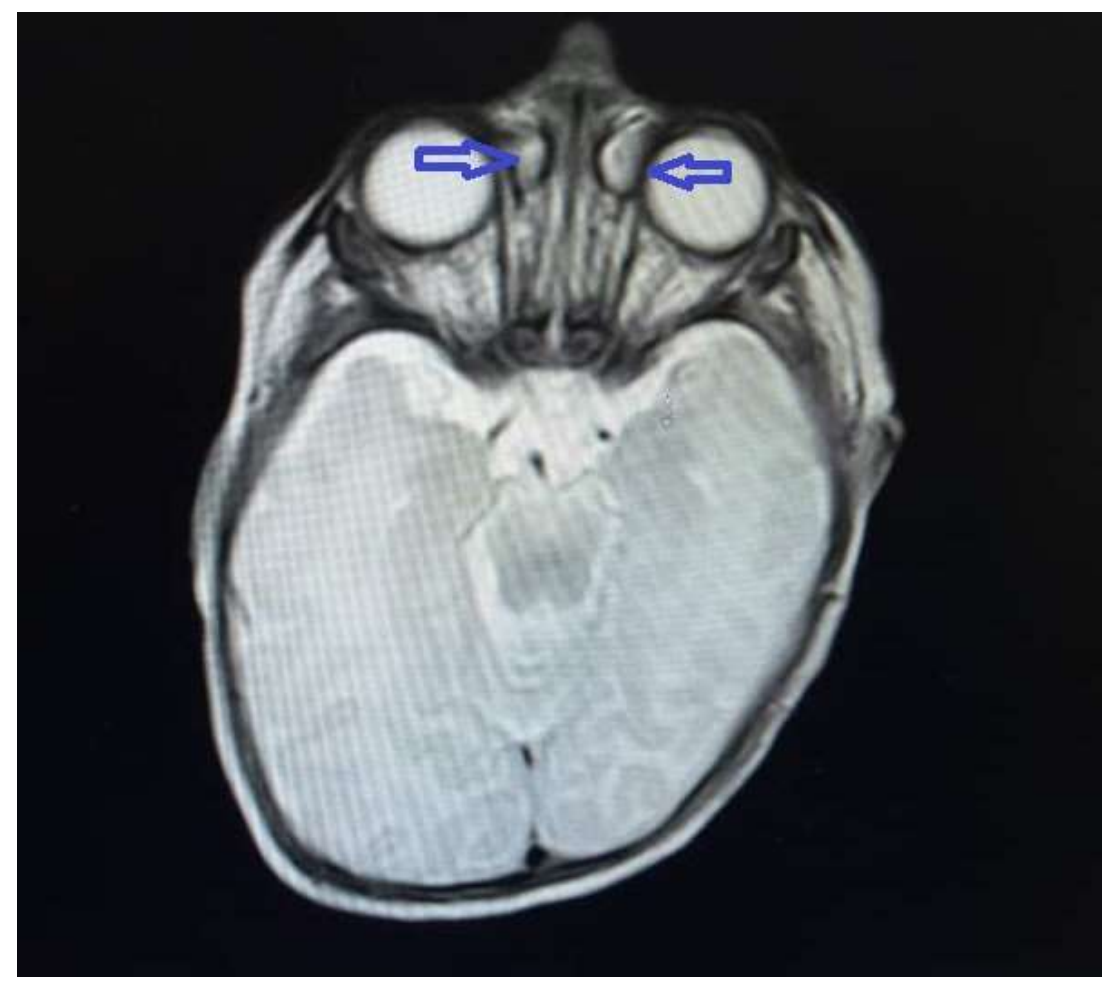

Figure 3. Axial view MRI of the paranasal sinus. Blue arrow showed bilateral dacryocystocele. 


\section{Discussion}

The nasal obstruction is potentially severe when it affects the newborns, as they are obligator nasal breather. The most common cause of nasal obstruction of the newborn and the infants are mucosal become oedematous secondary to viral rhinitis or idiopathic rhinitis of the infants [4]. However, it is important to exclude nasal anatomical anomalies such as choana atresia, congenital dacryocystocele and CNPAS.

To the best of our knowledge, there is no reported case of concurrent congenital dacrocystocele and nasal pyriform aperture stenosis in another journal yet. As in our case, the patient had two different congenital anomalies that never been apart or known as associated anomalies.

The congenital dacryocystocele was described as an obstruction of the nasolacrimal system and with an uncommon cause of respiratory dysfunction of the newborns, when expanded to the nasal cavity [5]. In the pathogenesis of dacryocystocele, when the sinus of Maier is absent, the superior and inferior canaliculi enter the lacrimal sac independently and at a hyperacute angle, this occurs in approximately $10 \%$ of normal infants and may predispose to kinking, creating a valve effect [6]. A non-patent valve of Hasner (distal lacrimal drainage system) is a prerequisite for the formation of a dacryocystocele and may exist in up to $73 \%$ of normal term infants [7]. When this valve mechanism coexists with obstruction of the valve of Hasner, the stage is set for the development of a dacryocystocele: fluid that is squeezed by the blinking motion enters the lacrimal sac but cannot exit [6]. The lacrimal sac can easily expand in the medial canthal region since there is no bony or tendinous structure to directly limit its expansion and since its wall is made of respiratory epithelium.

No associated anomalies have been described. Consequence anomalies include an enlarged lacrimal duct in the maxilla and lacrimal bone, a medial deviation of the inferior turbinates, and more rarely of the septum. Rarely, the appearance of hypertelorism is produced by the extra soft tissue medial to the eye [8]. Clinically, dacryocystocele presents as a grey-bluish cystic swelling in medial canthal area which typically present at birth and often resolved spontaneously with conservative management [9]. For differential diagnosis nasal obstruction with paranasal masses which is could be dacryocystocele, encephalocele, dermoid, haemangioma, mucocele, nasal glioma, sebaceous cyst and dacryocystitis [10].

CNPAS is an uncommon cause of nasal obstruction of the newborn. There have been only 2 reported cases of CNPAS in Malaysia [11]. It is characterized by an abnormal bony overgrowth of the nasal process of the maxilla into the nasal cavity [12]. There are two theories about the pathogenesis of CNPAS; deficiency of the primary palate, associated with a triangular hard palate and bony overgrowth in the nasal process of the maxilla, with the normal-shaped palate [12], which probably occurs at 4 months of fetal development [13], resulting in both cranial and facial anomalies of the midline head because CNPAS is a microform of holoprosencephaly (most likely hypothesis), which is a malformation resulting from incorrect cleavage of the embryonic prosencephalon [14]. The resulting brain malformation is variable (small forebrain vesicle, the incomplete formation of hemispheres, single ventricle), as are the facial anomalies (anophthalmia, cyclopia, ethmocephaly, cebocephaly, hypotelorism, flat nasal bridge, maxillary agenesis, median cleft lip or single central incisor [15]. The link between holoprosencephaly and CNPAS is confirmed by the frequency of some of these anomalies associated with the nasal disorder. The causal factors of holoprosencephaly are diverse; both autosomal dominant and autosomal recessive modes of transmission have been described, and there are also associations with trisomy 13, trisomy 18 , fetal alcohol syndrome and maternal type 1 diabetes [14].

As in our case, there is no related or associated anomaly that could cause it. However, the risk factor that most probable to occur together is the mother who had GDM on subcutaneous insulin.

Computed tomography (CT) scan is the choice of imaging investigation for both anomalies. The dacryocystocele features include nasolacrimal duct dilatation, cystic mass involving the medial canthus or nasal cavity, superior displacement of the inferior turbinate and contralateral shift of nasal septum. While the pyriform aperture is considered to be stenotic when the transversal diameter of each aperture is lower or equal to 3 
$\mathrm{mm}$ or the total transversal diameter of the pyriform aperture is lower than $8-11 \mathrm{~mm}$ in a normal newborn [16]. Ultrasound is a simple and non-invasive method that can be used without sedation to differentiate dacryocystocele from other intranasal mass [17]. The sonographic appearance pointed to the diagnosis of dacryocystocele include a medial cystic mass that in communication with the dilated nasolacrimal duct. Ultrasound also allows examination of the content of dacryocystocele which contains fluid or debris in the nasolacrimal sac [18]. MRI is another important imaging in both anomalies and is the method of choice allowing better differentiation between the solid and cystic components of nasolacrimal drainage apparatus lesion [19]. It is useful to study the disease relation with central nervous system before carrying out any surgical intervention.

The treatment of dacryocystocele may be conservative in the absence of respiratory commitment, or surgical intervention such as endoscopic marsupialization of the cyst when respiratory commitment that interferes with feeding or when the parents are not very confident to maintain the child at home with nasal obstruction [5]. In CNPAS, if the patients obtain a good breathing and adequate dietary ingestion with nasal washing, they can be clinically managed, but the surgical enlargement of the pyriform aperture is recommended in those patients with breathing and feeding difficulty [20].

In our case, both congenital anomalies are present and the patient also had a nasal obstruction. Surgical intervention is very beneficial for the patient. The patient underwent marsupialization of dacryocystocele and drilling of the stenotic part.

Results of surgical repair are satisfactory with the improvement of respiratory distress, apneic episodes and feeding problems. Postoperative treatment is important, using decongestants and nasal humidification for several weeks associated with some patients with treatment of gastroesophageal reflux. Finally, it is crucially important of suctioning into narrow nostrils, in postoperative management, to avoid mucosal inflammation and synechiae.

\section{Conclusion}

In conclusion, both congenital bilateral dacryocystocele with concomitant nasal pyriform aperture stenosis is a very rare case and not in associated anomalies have been described above. However it still possible to occur with the risk of GDM mother on subcutaneous insulin. The role of $\mathrm{CT}$ scan and MRI is the most important part for the diagnosis in a neonate with respiratory distress, feeding difficulties or query congenital nasal anomaly. In the case of severe nasal obstruction or respiratory dysfunction as in this case report, surgery needs to be performed and prompt surgical treatment is mandatory.

\section{References}

[1] Wong RK, Vander Veen DK. Presentation and management of congenital dacryocystocele. Pediatrics. 2008; 122(5):e1108-12.

[2] Hengerer AS, Brickman TM, Jeyakumar A: Choanal atresia: embryologic analysis and evolution of treatment, a 30-year experience. Laryngoscope. 2008; 118:862-866.

[3] Thomas EM, Gibikote S, Panwar J, Mathew J: Congenital nasal pyriform aperture stenosis: a rare cause of nasal airway obstruction in a neonate. Indian J Radiol Imaging. 2010; 20:266268.

[4] Brachlow A, Schwartz RH, Bahadori RS. Intranasal mucocele of the nasolacrimal duct: an important cause of neonatal nasal obstruction. Clinical Pediatrics. 2004; 43(5):479-81.

[5] Calcaterra VE, Annino DJ, Carter BL, Woog JJ. Congenital nasolacrimal duct cysts with nasal obstruction. Otolaryngology-Head and Neck Surgery. 1995; 113(4):481-4.

[6] Jones LT, Wobig JL. Surgery of the eyelids and lacrimal systems. Birmingham: Aesculapius. 1976; p162-4.

[7] Cassady JV. Development anatomy of the nasolacrimal duct. Arch Opthalmology. 1952; 47(2):141-158.

[8] John PR, Boldt D. Bilateral congenital nasolacrimal sac mucoceles with nasal extension. Pediatric Radiology. 1990; 20:285-286. 
[9] Veleva N, Chernodrinska V, Mladenov O. Bilateral congenital dacryocystocele-a case report. Biomed Res. 2018; 29(10):2134-5.

[10] Pujari A. Congenital dacryocystocele. BMJ Case Rep. 2016; 2016.

[11] Krishnamoorthy, M, Umbaik, N, Mohamad, $H$, Zaidin, A. Congenital nasal pyriform aperture stenosis: a rare condition treated successfully by expectant management. Pediatria i Medycyna Rodzinna. 2020; 16(1),113-117.

[12] Ey EH, Han BK, Towbin RB, Jaun WK. Bony inset stenosis as a cause of nasal airway obstruction. Radiology. 1988; 168:477-479.

[13] Brown OE, Myer CM, Manning SC. Congenital nasal pyriform aperture stenosis. Laryngoscope. 1989; 99(1):86-91.

[14] Arlis H, Ward RF. Congenital nasal pyriform aperture stenosis: isolated abnormality vs developmental field defect. Arch Otolaryngology Head and Neck Surgery. 1992; 118(9):989-991.

[15] Lo FS, Lee YJ, Lin SP, Shen EY, Huang JK, Lee KS. Solitary maxillary central incisor and congenital nasal pyriform aperture stenosis. Eur J pediatr. 1998; 157(1):39-44.

[16] Rollins N, Booth T, Biavati M. Case 40: Congenital pyriform aperture stenosis. Radiology. 2001; 221(2):392-4.

[17] Cavazza S, Laffi GL, Lodi L, Tassinari G, Dall'Olio D. Congenital dacryocystocele: diagnosis and treatment. Acta Otorhinolaryngol Ital. 2008 Dec; 28(6):298-301.

[18] Bachelard-Serra M, Chau C, Farinetti A, Roman S, Triglia JM, Nicollas R. Prenatal diagnosis of congenital dacryocystocele. Int J Pediatr Otorhinolaryngol. 2013; 77(5):847-9.

[19] Raslan OA, Ozturk A, Pham N, Chang J, Strong EB, Bobinski M. A comprehensive review of cross- sectional imaging of the nasolacrimal drainage apparatus: What radiologists need to know. Am J Roentgenol. 2019; 213(6):1331-40.

[20] Lee JJ, Bent JP, Ward RF. Congenital nasal pyriform aperture stenosis: non-surgical management and long-term analysis. International Journal of Pediatric Otorhinolaryngology. 2001; 60(2):167-71. 